\title{
JURISDIÇÃO E ASPECTOS AMBIENTAIS NA ARBITRAGEM NO MAR DA CHINA MERIDIONAL (FILIPINAS VS. CHINA)
}

\author{
JURISDICTION AND ENVIRONMENTAL ISSUES IN THE SOUTH CHINA SEA \\ ARBITRATION (PHILIPPINES v. CHINA)
}

\author{
JURISDICCIÓN Y ASPECTOS AMBIENTALES EN LA ARBITRAJE DEL MAR DEL \\ SUR DE CHINA (FILIPINAS C. CHINA)
}

\author{
AleXANDRe Pereira da SiLVA \\ http:// orcid.org/0000-0001-8707-8641 / http:/ / lattes.cnpq.br/7575113722116695 / alexandre@whu.edu.cn \\ Wuhan University China Institute of Boundary and Ocean Studies (CIBOS) \\ Wuhan, Hubei, China
}

\begin{abstract}
RESUMO
O artigo examina os aspectos jurisdicionais e ambientais da arbitragem no Mar da China Meridional (Filipinas vs. China) a partir do estudo do laudo arbitral sobre jurisdição e admissibilidade de 29 de outubro de 2015 e do laudo arbitral (mérito) de 12 de julho de 2016. Dois são os objetivos principais desse estudo. Em primeiro lugar, demonstrar que a corte arbitral constituída sob o anexo VII da Convenção das Nações Unidas sobre o Direito do Mar não tinha jurisdição sobre o caso. Em segundo lugar, examinar a parte do laudo arbitral (mérito) referente a obrigação de proteger e preservar o meio ambiente marinho. Defende-se que a recusa da China em participar de qualquer ato ligado à arbitragem resultou em uma avaliação rigorosa por parte da corte, especialmente no tocante as questões ambientais. 0 artigo emprega o método hipotético-dedutivo, tendo como suporte fundamental a análise dos mencionados laudos arbitrais e estudos doutrinários.
\end{abstract}

Palavras-chave: Arbitragem; Jurisdição; Meio Ambiente Marinho; Mar da China Meridional.

\begin{abstract}
The article examines jurisdiction and environmental aspects of the South China Sea arbitration (Philippines v. China) through the analyzes of the award on jurisdiction and admissibility of 29 October 2015 and the award (merits) of 12 July 2016. The main goal of this article is twofold. First, to demonstrate that the arbitral tribunal established under annex VII of the United Nations Convention on the Law of the Sea had not jurisdiction over the case. Second, to examine the part of the award (merits) concerning the obligation to protect and preserve the marine environment. It is argued that the refuse of China to take part in any act referring the arbitration led to a rigorous assessment by the court, especially regarding environmental issues. The paper used the hypothetical-deductive model supported by the analysis of the said awards and doctrinal studies.
\end{abstract}

Keywords: Arbitration; Jurisdiction; Marine Environment; South China Sea.

\section{RESUMEN}

El artículo examina la jurisdicción y los aspectos ambientales del arbitraje del Mar del Sur de China (Filipinas c. China) a través del análisis del laudo arbitral sobre admisibilidad y competencia de 29 octubre de 2015 y del laudo arbitral sobre el fondo de 12 julio de 2016. El objetivo principal de este artículo es doble. Primero, demonstrar que el tribunal arbitral constituido al amparo del anexo VII de la Convención de las Naciones Unidas sobre el Derecho de Mar no tenía jurisdicción sobre el caso. Segundo, examinar la parte del laudo sobre el fondo en relación con la obligación de proteger y preservar el ecosistema marino. Se argumenta que el rechazo de China a participar de cualquier acto del procedimiento arbitral condujo a una evaluación rigurosa por parte del tribunal, en especial con respecto a cuestiones ambientales. El trabajo utilizó el modelo hipotético-deductivo respaldado por el análisis de dichos laudos y estudios doctrinales.

Palabras clave: Arbitraje; Competencia; Ecosistema marino; Mar del Sur de China. 


\section{SUMÁRIO}

INTRODUÇÃO; 1 A ARBITRAGEM NO MAR DA CHINA MERIDIONAL (FILIPINAS vs. CHINA); 2 AS QUESTÕES AMBIENTAS NO LAUDO ARBITRAL (MÉRITO): AS ALEGAÇÕES DAS FILIPINAS E A "DEFESA" DA CHINA; 2.1 As alegações das Filipinas; 2.1.1 Práticas pesqueiras predatórias e exploração de espécies ameaçadas ou em perigo de extinção; 2.1.2 Atividades chinesas de construção em sete formações insulares nas ilhas Spratly; 2.2 A "defesa" da China; 2.2.1 Práticas pesqueiras predatórias e exploração de espécies ameaçadas ou em perigo de extinção; 2.2.2 Atividades chinesas de construção em sete formações insulares nas ilhas Spratly; 3 AS CONSIDERAÇÕES DA CORTE ARBITRAL SOBRE OS ASPECTOS AMBIENTAIS; 3.1 Jurisdição; 3.2 Disposições relevantes da CNUDM; 3.3 Práticas pesqueiras predatórias e exploração de espécies ameaçadas ou em perigo de extinção; 3.4 Atividades chinesas de construção em sete formações insulares nas ilhas Spratly; CONCLUSÃO; REFERÊNCIAS.

\section{INTRODUÇÃO}

O artigo examina a jurisdição e os aspectos ambientais apresentados nos laudos arbitrais - jurisdição e admissibilidade e mérito - do caso do Mar da China Meridional envolvendo as Filipinas e a China, uma das disputas mais rumorosas dos últimos anos na esfera jurídica internacional.

Iniciada em janeiro de 2013 por iniciativa das Filipinas, a arbitragem foi prontamente rejeitada pela China, que não participou de qualquer ato da contenda jurídica. Ainda assim, a corte arbitral constituída sob o anexo VII da Convenção das Nações Unidas sobre o Direito do Mar (CNUDM ou “Convenção") entendeu que tinha jurisdição sobre as questões pleiteadas pelas Filipinas (laudo arbitral de jurisdição e admissibilidade de 29 de outubro de 2015), decidindo sobre o mérito delas no laudo arbitral divulgado em 12 de julho de $2016 .{ }^{1}$

0 problema central deste artigo, portanto, consiste em examinar como a corte arbitral lidou com esses dois aspectos. Para responder esse questionamento, o trabalho empregou o método hipotético-dedutivo, por meio da análise dos mencionados laudos arbitrais e pesquisa bibliográfica. Parte-se da hipótese de que a rejeição da China em participar da arbitragem foi duplamente punida pela corte arbitral: em primeiro lugar, quando a corte entendeu que tinha jurisdição sobre o caso e, em segundo lugar, quando a corte examinou de maneira acentuadamente crítica os aspectos ambientais levantados pelas Filipinas. Dessa forma, dois são os objetivos deste trabalho. De um lado, examinar os aspectos jurisdicionais do caso da Mar da

\footnotetext{
${ }^{1}$ Os laudos da corte arbitral empregam jurisdiction, termo que pode ser traduzido para o Português tanto por "jurisdição" como por "competência". O autor optou pelo uso de "jurisdição" em sentido amplo, porque tanto a corte arbitral quanto a China utilizam a palavra indistintamente para designar tanto "jurisdição" como "competência" e sua diferenciação é pouco pertinente para o escopo esse texto.
} 
China Meridional e, de outro lado, considerar os dois aspectos principais do laudo arbitral (mérito): as alegadas práticas pesqueiras predatórias e as atividades de construção desenvolvidas pela China em algumas formações insulares na região das ilhas Spratly.

0 artigo está estruturado da seguinte maneira. 0 item 1 trata de contextualizar tanto a importância geopolítica do Mar da China Meridional como os aspectos centrais da arbitragem, mormente a questão jurisdicional. 0 item 2 versa sobre as questões ambientais suscitadas pelas Filipinas, bem como uma possível "defesa" chinesa, tanto no tocante às alegadas práticas pesqueiras predatórias como as atividades construtivas chinesas em algumas características marítimas. Por fim, o item 3 examina o laudo arbitral (mérito) no tocante aos aspectos anteriormente mencionados.

\section{A ARBITRAGEM NO MAR DA CHINA MERIDIONAL (FILIPINAS vS. CHINA)}

O Mar da China Meridional (South China Sea) é um mar semifechado localizado no Sudeste Asiático, com uma área de cerca de 3,5 milhões de $\mathrm{km}^{2}$, que conecta os oceanos Pacífico (leste) e Índico (sul). A região abrange os limites marítimos de seis Estados: Brunei Darussalam, China, Filipinas, Indonésia, Malásia e Vietnã, além de Taiwan. ${ }^{2}$ Desses sete atores regionais, somente a Indonésia não tem reinvindicações na área. ${ }^{3}$ Os seis Estados são partes da CNUDM. $^{4}$

O Mar da China Meridional é caracterizado por inúmeras ilhas, ilhotas, rochedos, baixios a descoberto, atóis e bancos de areia. Em razão da dificuldade de descrever geográfica e juridicamente cada uma delas, como será analisado adiante, é usual a utilização da expressão “características geológicas” ou “formações insulares” para mencioná-las sem, no entanto, entrar no mérito se tal elemento geológico é uma ilha, um rochedo ou um baixio a descoberto, para os

\footnotetext{
2 Taiwan, por não ser reconhecido como Estado, não pode se tornar parte da CNUDM; no entanto, em 1998, adotou legislação interna reivindicando zonas marítimas tais como as previstas na CNUDM. SONG, Yann-Huei; ZOU, Keyuan. Maritime Legislation on Mainland China and Taiwan: Developments, Comparison, Implications, and Potential Challenges for the United States. Ocean Development \& International Law, vol. 31, 2000. p. 304.

${ }^{3}$ Cingapura também pode ser considerado um Estado costeiro, já que uma de suas ilhas (Pedra Branca) está localizada neste mar. Além disso, se o golfo da Tailândia for considerado como um braço do Mar da China Meridional, então, o Camboja e a Tailândia podem ser qualificados com Estados litorâneos desse mar.

${ }^{4}$ BECKMAN, Robert. The UN Convention on the Law of the Sea and the Maritime Disputes in the South China Sea. American Journal of International Law, vol. 107, n. 1, 2013. p. 142.
} 
fins dos artigos 13 e 121 da CNUDM. ${ }^{5}$ As disputas estão concentradas em quatro pontos da região: as ilhas Paracel (Xisha Qundao), Spratly (Nansha Qundao), Pratas (Dongsha Qundao) e Macclesfield Bank (Zhongsha Qundao). ${ }^{6}$

Dois elementos precisam ser agregados para entender o contexto atual das disputas no Mar da China Meridional. Primeiramente, a importância estratégica das linhas comerciais, que ligam o Oceano Índico ao Nordeste Asiático, incluindo-se os portos da China, Coreia do Sul, Japão e Rússia. Por ano, cerca de US\$ 5,3 trilhões de dólares em mercadorias - algo em torno de um quarto do comércio global de mercadorias - cruzam esse mar; além disso, um terço do comércio global de petróleo e mais da metade do comércio de gás natural liquefeito passam pelo Mar da China Meridional. ${ }^{7}$

Em segundo lugar, os recursos naturais da região: o considerável potencial pesqueiro e, em especial, as ricas reservas de petróleo e gás natural. Números da US Energy Information Administration estimam que o Mar da China Meridional possua algo em torno de 11 bilhões de barris de petróleo e 190 trilhões de pés cúbicos de gás natural, entre reservas provadas e prováveis. Além disso, para o US Geological Survey, devem ser adicionados a esses números 12 bilhões de barris de petróleo e 160 trilhões de pés cúbicos de gás natural que poderiam ser ainda descobertos na região. ${ }^{8}$

Em termos jurídicos, a disputa iniciou-se em 22 de janeiro de 2013, quando o Ministério dos Negócios Estrangeiros das Filipinas entregou ao Embaixador da China em Manila uma nota

\footnotetext{
${ }^{5}$ Nos termos do artigo 13 da CNUDM: “1. Um baixio a descoberto é uma extensão natural de terra rodeada de água, que, na baixa-mar, fica acima do nível do mar, mas que submerge na preia-mar. Quando um baixio a descoberto se encontre, total ou parcialmente, a uma distância do continente ou de uma ilha que não exceda a largura do mar territorial, a linha de baixa-mar desse baixio pode ser utilizada como linha de base para medir a largura do mar territorial; 2. Quando um baixio a descoberto estiver, na totalidade, situado a uma distância do continente ou de uma ilha superior à largura do mar territorial, não possui mar territorial próprio". Já o artigo 121 versa sobre o regime das ilhas da seguinte forma: “1. Uma ilha é uma formação natural de terra, rodeada de água, que fica a descoberto na preia-mar; 2 . Salvo o disposto no parágrafo 3, o mar territorial, a zona contígua, a zona econômica exclusiva e a plataforma continental de uma ilha serão determinados de conformidade com as disposições da presente Convenção aplicáveis a outras formações terrestres; 3 . Os rochedos que, por si próprios, não se prestam à habitação humana ou à vida econômica não devem ter zona econômica exclusiva nem plataforma continental".

${ }^{6}$ Os números das características geológicas tanto em torno da região das Paracel como das Spratly variam consideravelmente. No caso das Spratly, muitos autores indicam que o número seria de 230 , podendo chegar a mais de 400. Durante as audiências de junho de 2015 na corte arbitral, o representante das Filipinas mencionou que seriam 750 formações insulares. Nas Paracel, a variação é menor, entre 20 a 35 características.

7 ZOU, Keyuan. The South China Sea. In: ROTHWELL, Donald; OUDE ELFERINK, Alex; SCOTT, Karen; STEPHENS, Tim (eds.). The Oxford Handbook of the Law of the Sea. Oxford: Oxford University Press, 2015. p. 627

${ }^{8}$ LIN, Kun-Chin; GERTNER, Andrés Villar. Maritime Security in the Asia Pacifc: China and the Emerging Order in the East and South China Seas. London: The Royal Institute of International Affairs/Chatham House, 2015. p. 5.
} 
verbal juntamente com uma Notificação e Declaração de Reivindicação (Notification and Statement of Claim) desejando iniciar os procedimentos arbitrais previstos na CNUDM, em especial o prescrito no artigo 287 e no anexo VII da CNUDM, no tocante às disputas sobre jurisdição marítima no Mar da China Meridional. ${ }^{9}$ As Filipinas diziam ter esgotado as vias políticas e diplomáticas para uma resolução pacífica negociada com a China sobre as questões marítimas, todas sem sucesso. ${ }^{10}$ A corte arbitral foi constituída em 21 de junho de 2013.

Os quinze pleitos filipinos podem ser sumarizados em três eixos inter-relacionados. Primeiro, as Filipinas solicitavam que a corte arbitral ${ }^{11}$ declarasse que os direitos e os deveres de ambas as partes no tocante às águas, o leito marinho e as características geológicas no Mar da China Meridional seriam aqueles previstos na CNUDM e que as reivindicações chinesas baseadas em "direitos históricos" inseridos na "linha dos nove traços" ("nine-dash line”) seriam inválidos e contrários à CNUDM (pleitos n. 1 e 2). Segundo, buscavam que a corte, nos termos da CNUDM, determinasse como algumas formações insulares ${ }^{12}$ - reivindicadas tanto pela China como pelas Filipinas -, deveriam ser caracterizadas, ou seja, se como ilhas, rochedos, baixios a descoberto ou bancos submersos (pleitos n. 3 a 8). Terceiro, as Filipinas queriam que a corte declarasse que a China tinha violado a Convenção ao interferir no exercício das liberdades e direitos soberanos das Filipinas por meio de construção de ilhas e práticas pesqueiras predatórias ao meio ambiente marinho da região (pleitos n. 9 a 15).

\footnotetext{
${ }^{9} \mathrm{O}$ artigo 287 da Convenção confere aos Estados-partes a escolha do procedimento para a solução de suas controvérsias. Nem as Filipinas nem a China fizeram uma declaração escrita escolhendo um dos meios específicos para a solução de disputas relativas à interpretação ou aplicação da CNUDM. Neste caso, a presunção recai sobre a arbitragem prevista no anexo VII da Convenção.

${ }^{10}$ PHILIPPINES. Republic of Philippines' Notification of Statement and Claim (Manila, 22 January 2013), para. 7. Disponível em: https://www.gov.ph/documents/20147/151042/20130122-Notification-andStatement-of-Claim-on-West-Philippine-Sea.pdf. Acesso em: 20 dez. 2019.

${ }_{11}$ As Filipinas indicaram um dos árbitros, o então juiz do Tribunal Internacional do Direito do Mar (TIDM) Rüdiger Wolfrum (Alemanha). 0 presidente do TIDM indicou os demais: Jean-Pierre Cot (França), Stanislaw Pawlak (Polônia), Alfred Soons (Países Baixos) e Chris Pinto (Sri Lanka, presidente). Pinto posteriormente renunciou ao cargo, sendo substituído pelo ex-juiz do TIDM Thomas Mensah (Gana), que também presidiu os trabalhos da corte arbitral. Como apontado por Tzeng, embora a corte arbitral tenha sido constituída de acordo com os termos do anexo VII da CNUDM não se deve ignorar o fato de que foi um juiz japonês - e o antagonismo entre a China e o Japão não é segredo - quem indicou os demais membros, sendo quatro dos cinco europeus, sugerindo que a corte arbitral não estaria em condições de examinar outras perspectivas de direito internacional. Além disso, é preciso considerar o próprio viés notadamente prójurisdicional do juiz Wolfrum. TZENG, Peter. Ukraine v. Russia and Philippines v. China: Jurisdiction and Legitimacy. Denver Journal of International Law and Policy, v. 46, n. 1, 2017, p. 17-18.

12 São nove características geológicas no total: Scarborough Shoal e outras oito que formam parte das ilhas Spratly (Cuarteron Reef, Fiery Cross Reef, Gaven Reef, Hughes Reef, Johnson Reef, Mischief Reef, Second Thomas Shoal e Subi Reef).
} 
Ciente dos possíveis obstáculos jurisdicionais para a constituição da corte e dos termos da Declaração da China de $2006^{13}$ - que excluiu as questões sobre delimitação marítima dos procedimentos compulsórios de solução de disputa previstos na CNUDM -, as Filipinas registraram que não buscavam que a arbitragem resolvesse questões sobre soberania territorial ou delimitação marítima na disputa com a China. ${ }^{14}$

Por outro lado, as Filipinas reconheceram que existia uma disputa com a China sobre a soberania de diversas formações insulares na região e reconheceram também que "as disputas com a China no Mar da China Meridional têm mais de uma camada". No entanto, as Filipinas consideravam que isso era totalmente irrelevante para o exame de jurisdição da corte arbitral já que "nenhuma das submissões [das Filipinas] exige que a corte expresse qualquer opinião quanto à extensão da soberania da China sobre território terrestre, ou de qualquer outro Estado". ${ }^{15}$

Em 19 de fevereiro de 2013, em nota verbal dirigida ao Ministério dos Negócios Estrangeiros das Filipinas a China rejeitou a arbitragem e devolveu a Notificação das Filipinas. Posteriormente, em reiteradas manifestações oficiais, a China confirmou sua posição de que não aceitaria e tampouco participaria de qualquer ato da arbitragem iniciada pelas Filipinas. Por outro lado, a China sempre reafirmou seu empenho em resolver os conflitos de modo pacífico através de negociações, propondo entre outras iniciativas o estabelecimento de um mecanismo de consultas regular bilateral sobre questões marítimas e a retomada do mecanismo de Confidence Building Measures estabelecido entre os dois países.

Em 7 de dezembro de 2014, a China publicou um documento sobre sua posição, o “Documento da República Popular da China com relação ao tema da jurisdição na arbitragem no

${ }^{13}$ Em 25 de agosto de 2006, a China fez a seguinte declaração sob o artigo 298 da CNUDM: "The Government of the People's Republic of China does not accept any of the procedures provided for in Section 2 of Part XV of the Convention with respect to all categories of disputes referred to in paragraph 1 (a) (b) and (c) of Article 298 of the Convention". Portanto, por essa declaração, a China excluiu de maneira explícita todas as disputas mencionadas no artigo 298.1 dos procedimentos compulsórios de solução de disputas, inclusive a arbitragem prevista no anexo VII da CNUDM. UNITED NATIONS. Status of Treaties. United Nations Convention on the Law of the Sea. Disponivel: https: / / treaties.un.org/pages/ViewDetailsIII.aspx?src=TREATY\&mtdsg_no=XXI-

6\&chapter=21\&Temp=mtdsg3\&clang=_en. Acesso em: $20 \mathrm{dez} .2019$.

14 PHILIPPINES. Arbitration under Annex VII of the United Nations Convention on the Law of the Sea. Republic of the Philippines v. People's Republic of China. Memorial of the Philippines, vol. I, 30 March $2014 . \quad$ Disponivel em: https://files.pcacpa.org/pcadocs/Memorial\%20of\%20the\%20Philippines\%20Volume\%20l.pdf. Acesso em: 20 dez. 2019.

15 PCA. PCA Case no. 2013-19. In the matter of an arbitration before an arbitral tribunal constituted under Annex VII to the 1982 United Nations Convention on the Law of the Sea between the Republic of the Philippines and the People's Republic of China, Award on Jurisdiction and Admissibility, 29 October 2015, para. 141. Traduções do original: "disputes with China in the South China Sea have more than one layer"; "[n]one of [the Philippines'] submissions require the Tribunal to express any view at all as to the extent of China's sovereignty over land territory, or that of any other state". 
Mar da China Meridional iniciada pela República das Filipinas” (doravante Position Paper), ratificando seu entendimento de que a corte arbitral não tinha jurisdição para considerar as questões suscitadas pelas Filipinas. Registrou, ainda, de maneira clara, que o documento não podia ser considerado como uma aceitação ou uma participação da China na mencionada arbitragem. ${ }^{16}$

No Position Paper a China expôs diversos pontos que já vinham sendo asseverados pelo menos desde 2009 quando se iniciou uma sucessão de notas verbais no âmbito das Nações Unidas em decorrência dos pleitos da Malásia e do Vietnã a plataformas continentais estendidas na área do Mar da China Meridional. A mais importante dessas notas diplomáticas foi a primeira nota verbal enviada pela China em que consta o mapa com a "linha dos nove traços", que provocou a reação de quase todos os outros Estados costeiros do Mar da China Meridional. ${ }^{17}$

A posição da China pode ser sintetizada em três pontos:

i) a essência do objeto da arbitragem é sobre a soberania territorial de várias características geológicas no Mar da China Meridional, questão que está além do escopo da CNUDM, já que o sistema de controvérsia estabelecido na Parte XV da Convenção versa somente sobre "a interpretação ou aplicação da Convenção";

ii) a China e as Filipinas acordaram, através de instrumentos bilaterais e da Declaração de Conduta das Partes no Mar da China Meridional (DOC), em resolver suas disputas através de negociações e que ao iniciar de maneira unilateral a arbitragem as Filipinas violavam compromissos de direito internacional;

iii) mesmo se fosse admitido que o objeto da arbitragem recaísse sobre a interpretação ou aplicação da CNUDM, este consistiria em última análise na delimitação marítima entre os dois países e, consequentemente, incidiria sobre a declaração feita pela China em 2006 nos termos do artigo 298 da CNUDM e depositada junto à ONU, que exclui questões de delimitação marítima da arbitragem compulsória e outros procedimentos obrigatórios de resolução de disputas.

Antes de examinar o mérito dos pleitos levantados pelas Filipinas, a corte arbitral reuniu-se em audiência em julho de 2015 para enfrentar as questões sobre jurisdição e admissibilidade a fim de assegurar-se "de que não só tem jurisdição sobre a controvérsia, mas também de que a pretensão está, de direito e de fato, bem fundamentada" (artigo $9^{\circ}$ do anexo

${ }^{16}$ CHINA. Position Paper of the Government of the People's Republic of China on the Matter of Jurisdiction in the South China Sea Arbitration Initiated by the Republic of the Philippines. Disponivel em: https://www.fmprc.gov.cn/nanhai/eng/snhwtlcwj_1/t1368895.htm. Acesso em: 20 dez. 2019.

17 SILVA, Alexandre Pereira da. Aspectos jurídicos e políticos das disputas no Mar da China Meridional. In: COSTA LIMA, Marcos (org.). Perspectivas asiáticas. Rio de Janeiro: Centro Internacional Celso Furtado de Políticas para o Desenvolvimento, 2016, p. 271-299. 
VII da CNUDM). Mesmo com a ausência da China, a corte considerou as objeções jurisdicionais suscitadas pelo governo chinês expostas no Position Paper de 2014, bem como em outras declarações, que pudessem potencialmente impedir à continuação do processo. Delegações da Indonésia, Japão, Malásia, Tailândia e Vietnã estiveram presentes como observadoras nas audiências.

Em 29 de outubro de 2015, a corte arbitral divulgou o laudo arbitral sobre jurisdição e admissibilidade (doravante LAJA). ${ }^{18}$ Preliminarmente, a corte recordou que os dois países são Partes da CNUDM e, portanto, ambos estão submetidos ao sistema de solução de controvérsias da Parte XV da CNUDM. Além disso, registrou que o artigo $9^{\circ}$ do anexo VII da CNUDM dispõe que “[...] a ausência de uma parte ou a não apresentação da defesa da sua causa não deve constituir impedimento aos procedimentos" e que nos termos tanto do artigo 296.1 da CNUDM como do artigo 11 do Anexo VII, o laudo é definitivo e tem força obrigatória para a China.

No entendimento da corte arbitral para definir se ela teria ou não jurisdição sobre a controvérsia, a corte deveria determinar, em primeiro lugar, se havia uma disputa entre as Partes no tocante aos pleitos trazidos pelas Filipinas e, em segundo lugar, se a controvérsia versava sobre à interpretação ou aplicação da CNUDM (para. 131 LAJA).

Sobre o primeiro aspecto, a corte arbitral reconheceu a existência de disputas territoriais entre a China e as Filipinas, mas frisou que: “A corte não aceita, no entanto, que como consequência da existência de uma disputa sobre soberania que a soberania seja também a caracterização apropriada para as reivindicações que as Filipinas submeteram nesse procedimento" (para. 152 LAJA). ${ }^{19}$

No tocante ao segundo aspecto, a corte entendeu que os pleitos filipinos eram ou sobre títulos marítimos ou sobre atividades chinesas no Mar da China Meridional e que, portanto, “as disputas entre as Partes referentes à interpretação ou aplicação da Convenção existem com relação aos temas levantados pelas Filipinas em todos os seus pleitos nesse procedimento" (para. 178 LAJA). ${ }^{20}$

\footnotetext{
18 PERMANENT COURT OF ARBITRATION (PCA). PCA Case no. 2013-19, In the matter of an arbitration before an arbitral tribunal constituted under Annex VII to the 1982 United Nations Convention on the Law of the Sea between the Republic of the Philippines and the People's Republic of China, Award on Jurisdiction and Admissibility, 29 October 2015. Disponível em: https://pcacases.com/web/sendAttach/2579. Acesso em: 20 dez. 2019.

19 Tradução do original: "The Tribunal does not accept, however, that it follows from the existence of a dispute over sovereignty that sovereignty is also the appropriate characterisation of the claims the Philippines has submitted in these proceedings".

${ }^{20}$ Tradução do original: "[...] disputes between the Parties concerning the interpretation and application of the Convention exist with respect to the matters raised by the Philippines in all of its Submissions in these proceedings".
} 
Consequentemente, a corte arbitral não aceitou as objeções jurisdicionais mencionadas pela China no Position Paper de que as controvérsias apresentadas pelas Filipinas se referiam à soberania sobre determinadas características geológicas (para. 153 LAJA).

Por outro lado, dos quinze pleitos filipinos, somente em três deles a corte arbitral entendeu de maneira inequívoca que tinha jurisdição - dois no tocante à condição de Scarborough Shoal, Johnson Reef, Cuarteron Reef e Fiery Cross Reef (n. 3 e 7) e outro referente à proteção do meio ambiente marinho em Scarborough Shoal e Second Thomas Shoal (n. 11) -, em outros sete pleitos a corte postergou o exame das questões jurisdicionais para o mérito - seja em razão da alegação de direitos históricos da China (n. 1 e 2), seja porque o pleito dependeria de uma decisão sobre se determinadas formações insulares seriam ilhas nos termos da CNUDM (n. 5, 8 e 9) ou porque o exame do pleito dependeria da condição de Mischief Reef e/ou Second Thomas Shoal; bem como se determinadas atividades desenvolvidas pela China teriam caráter militar (n. 12 e 14).

Em outros quatro pleitos, a corte entendeu que tinha jurisdição "sujeita à ressalva com respeito a possíveis efeitos de sobreposição de direitos" 21 (n. 4 e 6) e "na medida em que os direitos reivindicados e a alegada interferência ocorreram no mar territorial de Scarborough Shoal"22 (n. 10 e 13). Em relação ao pleito n. 15 - "a China deve desistir de outras atividades e reivindicações ilegais" ${ }^{23}$-, a Corte solicitou que as Filipinas esclarecessem quais atividades estariam potencialmente relacionadas a esse pedido (para. 412 LAJA). Posteriormente, no laudo arbitral de mérito (doravante LAM) ${ }^{24}$, a corte arbitral reconheceu que não tinha jurisdição sobre o pleito n. 14 (letras a, b e c) que envolve atividades militares, nos termos do artigo 298.1(b) da CNUDM e da Declaração da China de 2006 (para. 1162 LAM).

Portanto, em diversos pleitos filipinos a decisão sobre se a corte arbitral teria ou não jurisdição ficou na dependência da determinação sobre a condição de diversos pontos do Mar da China Meridional, isto é, definir se determinada característica geológica era uma ilha, um rochedo ou um baixio a descoberto passou a ser um elemento central da arbitragem, especialmente porque muitas dessas, tais como Scarborough Shoal, Mischief Reef, Second

\footnotetext{
${ }^{21}$ Tradução do original: "[...] subject to a caveat with respect to the possible effects of any overlapping Entitlements".

22 Tradução do original: "[...] to the extent that the claimed rights and alleged interference occurred within the territorial sea of Scarborough Shoal".

${ }^{23}$ Tradução do original: "China shall desist from further unlawful claims and activities".

24 PERMANENT COURT OF ARBITRATION (PCA). PCA Case no. 2013-19, In the matter of the South China Sea arbitration before an arbitral tribunal constituted under Annex VII to the 1982 United Nations Convention on the Law of the Sea between the Republic of the Philippines and the People's Republic of China, Award, 12 July 2016. Disponível em: https://pcacases.com/web/sendAttach/2086. Acesso em: 20 dez. 2019.
} 
Thomas Shoal e Johnson Reef estão a menos de 200 milhas marítimas da costa das Filipinas, em princípio, dentro da zona econômica exclusiva (ZEE) e plataforma continental do país. ${ }^{25}$

Se, por exemplo, todas essas formações insulares gerassem ZEEs e plataformas continentais de até $\mathbf{2 0 0}$ milhas marítimas e se todas elas pertencessem a China, inevitavelmente teria que haver um acordo de delimitação marítima entre a China e as Filipinas, nos termos dos artigos 74 e 83 da CNUDM, o que impediria a corte arbitral de examinar tais questões, em razão da mencionada declaração da China de 2006 sob o artigo 298 da CNUDM. Conhecedora desse possível obstáculo jurisdicional, a corte arbitral deixou esse assunto para ser enfrentado juntamente com o mérito.

No LAM, as questões sobre a condição das características geológicas no Mar da China Meridional foram examinadas entre os parágrafos 279 e 648. Inicialmente, e dessa forma afastando qualquer óbice jurisdicional, a corte arbitral considerou que a controvérsia se referia à condição das formações insulares e não sobre à soberania delas. Ou seja, a corte arbitral entendeu que poderia julgar essa questão meramente à luz do artigo 13 (baixios a descoberto) e do artigo 121 (regime das ilhas), por se tratar de "intepretação e aplicação da Convenção", desconsiderando a disputa sobre a soberania territorial dessas formações insulares. ${ }^{26}$

Primeiramente, a corte dividiu as características geológicas em disputa em duas categorias: baixios a descoberto e características acima do nível do mar (high-tide features). Identificou na primeira categoria: Hughes Reef, Gaven Reef (sul), Subi Reef, Mischief Reef e Second Thomas Shoal; e na segunda: Scarborough Shoal, Cuarteron Reef, Fiery Cross Reef e Gaven Reef (norte) (para. 382-384 LAM).

Em um segundo momento, a corte passou ao exame das seis maiores características geológicas que estão acima do nível do mar nas ilhas Spratly: Itu Aba (Taiping Dao), Thitu (Zhongye Dao), West York (Xiyue Dao), Spratly (Nanwei Dao), North-East Cay (Beizi Dao) e SouthWest Cay (Nanzi Dao). No entendimento da corte, nenhuma delas é capaz de sustentar a vida

\footnotetext{
${ }^{25}$ Nos limites desse trabalho, é importante destacar que uma ilha gera mar territorial, zona econômica exclusiva e plataforma continental, enquanto um rochedo, apenas mar territorial (e zona contígua), de acordo com o artigo 121 da CNUDM. Já um baixio a descoberto não possui mar territorial próprio, mas quando se encontre, total ou parcialmente, a uma distância do continente ou de uma ilha que não exceda a largura do mar territorial, o baixio a descoberto poderá ser utilizado como apoio da linha de base para medir a largura do mar territorial, nos termos do artigo 13 da CNUDM. Vide nota de rodapé n. 5.

${ }^{26}$ PERMANENT COURT OF ARBITRATION (PCA). PCA Case no. 2013-19. In the matter of the South China Sea arbitration before an arbitral tribunal constituted under Annex VII to the 1982 United Nations Convention on the Law of the Sea between the Republic of the Philippines and the People's Republic of China, Award, 12 July 2016. Disponível em: https://pcacases.com/web/sendAttach/2086. Acesso em: 20 dez. 2019.
} 
humana nos termos do artigo 121.3 da CNUDM, chegando a mesma conclusão em relação a todas as demais características acima do nível do mar (para. 622-625 LAM). Desse modo, a corte arbitral concluiu que "nenhuma das características acima do nível do mar nas ilhas Spratly é capaz de sustentar a habitação humana ou vida econômica por si mesma, a consequência do artigo 121.3 é que tais características não devem ter zona econômica exclusiva ou plataforma continental" (para. 626 LAM). ${ }^{27}$

Portanto, no entendimento da corte arbitral, todas as formações insulares na área em disputa ou são baixios a descoberto ou são rochedos, não havendo ilhas (nos termos do artigo 121, para. 1 e 2 da (NUDM) na região em disputa. Considerando ainda que Mischief Reef e Second Thomas Shoal - que estão a menos de 200 milhas marítimas da costa das Filipinas - são apenas baixios a descoberto e que, nessa condição, não podem ser reivindicados pela China, já que fazem parte da ZEE e plataforma continental das Filipinas. ${ }^{28}$ Dessa forma, na visão da corte, não existe qualquer possiblidade de sobreposição de áreas marítimas geradas por qualquer característica geológica reivindicada pela China, inexistindo necessidade de delimitação marítima entre os países (para. 647 LAM).

Esse entendimento foi duramente criticado por Nordquist e Phalen que consideraram que a corte errou na interpretação do artigo 121 da Convenção com relação a Itu Aba (Taiping Dao), já que esta é efetivamente uma ilha nos termos do dispositivo. Se essa formação insular tivesse sido considerada uma ilha, teria direito a estabelecer uma ZEE de até 200 milhas marítimas que se sobreporia com ZEEs de outros Estados costeiros, inclusive das Filipinas. Nesse cenário haveria uma disputa sobre limites marítimos, que nos termos da declaração chinesa de 2006 impediria o exame pela corte arbitral. ${ }^{29}$

É valido também recordar que a decisão da corte sobre esse ponto contrasta frontalmente com o anteriormente defendido por um dos seus árbitros, o professor Soons:

${ }^{27}$ Tradução do original: "[...] none of the high-tide features in the Spratly Islands is capable of sustaining human habitation or an economic life their own, the effect of Article 121(3) is that such features shall have no exclusive economic zone or continental shelf".

${ }^{28}$ No entendimento da corte arbitral, citando o julgamento da $\mathrm{CIJ}$ no caso Territorial and Maritime Dispute (Nicaragua v. Colombia): "Accordingly, and as distinct from land territory, the Tribunal subscribes to the view that 'low-tide elevations cannot be appropriated, although 'a coastal State has sovereignty over low-tide elevations which are situated within its territorial sea, since it has sovereignty over the territorial sea itself'" (para. 309 LAM). Entretanto, não se trata de um posicionamento pacífico, já que, por exemplo, a arbitragem do caso Eritrea v. Yemen decidiu que determinadas "ilhas, ilhotas, rochedos e baixios a descoberto" estavam sujeitas à soberania territorial tanto da Eritreia como do lêmen. Award of the Arbitral Tribunal in the First Stage of the Proceedings (Territorial Sovereignty and Scope of the Dispute).

${ }^{29}$ NORDQUIST, Myron H. PHALEN, William G. Interpretation of UNCLOS Article 121 and Itu Aba (Taiping) in the South China Sea Arbitration. In: NORDQUIST, Myron H.; MOORE, John Norton; LONG, Ronán (eds.). International Marine Economy: Law and Policy. Leiden: Brill, 2017. p. 3. 
[...] a definição de rochedo e seu direito a espaços marítimos, assim como a definição e o direito das ilhas em geral, constitui uma parte inerente da delimitação marítima entre Estados opostos/adjacentes e, como a prática estatal claramente evidencia, esses assuntos não darão origem a controvérsias, a menos que tal delimitação esteja em disputa. ${ }^{30}$

Sem entrar no mérito da questão se a interpretação do artigo 121 da CNUDM foi ou não correta por parte da corte arbitral, o fato que não pode ser esquecido é que a corte não poderia ter desconsiderado as disputas sobre soberania territorial no Mar da China Meridional reconhecidas tanto pelas Filipinas como pela China - para simplesmente fazer a interpretação do artigo 121 da CNUDM à luz dos pleitos filipinos, como se a questão soberana fosse meramente acessória, quando de fato é a principal.

Não parece haver nenhum precedente em tribunais ou cortes internacionais em que se fez a análise da condição sobre determinada formação insular quando a soberania territorial sobre aquela característica estava em disputa. ${ }^{31}$ Isso ocorre em razão de um princípio geral do direito internacional amplamente reconhecido na doutrina do direito do mar e em diversos julgamentos da Corte Internacional de Justiça $(\mathrm{CIJ})$, de que "a terra domina o mar" (the land dominates the sea), ou seja, é o território terrestre que confere ao Estado costeiro o direito às águas que banham seu litoral.

Como considerado no julgamento do caso "Catar vs. Bahrein" pela ClJ: "os direitos marítimos derivam da soberania do Estado costeiro sobre o território, um princípio que pode ser resumido como 'a terra domina o mar' [...] assim, a situação do território terrestre deve ser tomada como ponto de partida para a determinação dos direitos marítimos". ${ }^{32}$

Esse ponto foi ressaltado pela China no Position Paper de 2014:

\footnotetext{
${ }^{30}$ SOONS, Alfred H. A.; KWIATKOWSKA, Barbara. Entitlement to Maritime Areas of Rocks Which Cannot Sustain Human Habitation or Economic Life their Own. Netherlands Yearbook of International Law, vol. 21, 1990. p. 181. Tradução do original: "[...] the definition of rocks and their entitlement to maritime spaces, like the definition and entitlement of islands in general, forms an inherent part of maritime boundary delimitation between opposite/adjacent States and, as State practice clearly evidences, these issues will not give rise to controversies unless such delimitation is in dispute".

31 WHOMERSLEY, Chris. The South China Sea: The Award of the Tribunal in the Case Brought by Philippines against China - A Critique. Chinese Journal of International Law, n. 15, 2016. p. 252.

32 INTERNATIONAL COURT OF JUSTICE (ICJ). Maritime Delimitation and Territorial Questions between Qatar and Bahrain. Merits, Judgment, ICJ Reports 2001, para. 185. Tradução do original: "maritime rights derive from the coastal State's sovereignty over the land, a principle which can be summarized as 'the land dominates the sea' [...] "it is thus the terrestrial territorial situation that must be taken as starting point for the determination of the maritime rights of a coastal State".
} 
Até aonde versa a presente arbitragem, sem primeiramente ter determinado a soberania territorial da China sobre as características marítimas no Mar da China Meridional, a corte arbitral não estará em posição de determinar a extensão sobre a qual a China pode reivindicar direitos marítimos no Mar da China Meridional nos termos da Convenção, sem mencionar se as reivindicações chinesas excedem a extensão permitida sob a Convenção. Entretanto, a questão da soberania terrestre está excluída do âmbito da Convenção. ${ }^{33}$

Consequentemente, enquanto não fosse determinada a soberania sobre as características geológicas que geram zonas marítimas - repita-se, assunto que está fora do escopo da CNUDM e, portanto, do mecanismo de solução de controvérsia da Parte XV -, nenhum dos pleitos filipinos deveria ter sido considerado pela corte arbitral. 0 mesmo valeria também para a "linha dos nove traços". ${ }^{34}$

Ainda sobre o tema das objeções jurisdicionais é importante frisar que no Position Paper a China anotou que existe um acordo entre os dois países - a "Declaração sobre a Conduta das Partes no Mar da China Meridional (DOC)" - para resolver as disputas por meio de consultas e negociações. ${ }^{35}$

Considerando que o artigo 281.1 da CNUDM dispõe que "[se as partes] em uma controvérsia relativa à interpretação ou aplicação da presente Convenção tiverem acordado em procurar solucioná-la por um meio pacífico de sua própria escolha", os procedimentos previstos na Parte XV "só serão aplicados se não tiver sido alcançada uma solução por esse meio e se o acordo entre as partes não excluir a possibilidade de outro procedimento". A corte arbitral considerou que "o melhor entendimento do artigo 281 requer algum tipo de declaração de exclusão de outros procedimentos" (para. 223 LAJA). A China sustentou que uma exclusão expressa é desnecessária. No entanto, mais adiante o LAJA complementou que "mesmo se a corte aceitasse que o recurso ao sistema de controvérsia da Parte XV pudesse ser implicitamente

33 CHINA. Position Paper of the Government of the People's Republic of China on the Matter of Jurisdiction in the South China Sea Arbitration Initiated by the Republic of the Philippines. Disponivel em: https://www.fmprc.gov.cn/nanhai/eng/snhwtlcwj_1/t1368895.htm. Acesso em: 20 dez. 2019. Tradução do original: "As far as the present arbitration is concerned, without first having determined China's territorial sovereignty over the maritime features in the South China Sea, the Arbitral Tribunal will not be in a position to determine the extent to which China may claim maritime rights in the South China Sea pursuant to the Convention, not to mention whether China's claims exceed the extent allowed under the Convention. But the issue of territorial sovereignty falls beyond the purview of the Convention".

34 YEE, Sienho. The South China Sea Arbitration: The Clinical Isolation and/or One-sided Tendencies in the Philippines' Oral Arguments. Chinese Journal of International Law, vol. 14, 2015, p. 430.

35 ASSOCIATION OF SOUTHEAST ASIAN NATIONS (ASEAN). Declaration on the Conduct of Parties in the South China Sea (DOC), assinada em 4 de novembro de 2002. Disponível em: http://asean.org/?static_post=declaration-on-the-conduct-of-parties-in-the-south-china-sea-2. Acesso em: 20 dez. 2019. 
excluído, a corte acredita que tal exclusão não pode ser subentendida no DOC" (para. 226 LAJA). ${ }^{36}$

Deste modo, o LAJA baseou-se em cinco grandes conclusões para afirmar sua jurisdição para julgar os pleitos filipinos. Primeiro, a corte rejeitou a objeção da China de que as disputas seriam na verdade sobre soberania territorial no Mar da China Meridional e, portanto, além da jurisdição da corte. Segundo, rejeitou o argumento exposto pela China no Position Paper de que as disputas entre as Partes seriam de fato sobre delimitação marítima e por isso excluída da jurisdição da corte em razão da Declaração da China de 2006 sob o artigo 298 da CNUDM. Ao contrário, para a corte, cada um dos pleitos n. 1 a 14 reflete uma disputa entre as partes no tocante a interpretação e aplicação da CNUDM. Terceiro, a corte rejeitou a posição da China de que as partes teriam concordado em resolver as disputas relacionadas ao Mar da China Meridional exclusivamente por meio de consultas e negociações. Quarto, considerou que nenhum outro Estado é indispensável no processo. Quinto, a corte entendeu que as Filipinas preenchiam os requisitos do artigo 283 da CNUDM de que as partes trocaram opiniões no que se refere à resolução das disputas.

O fato, contudo, é que os pleitos filipinos giram todos em torno da delimitação marítima entre os dois países e, portanto, inevitavelmente envolvem questões de soberania sobre determinadas características geológicas (ilhas, rochedos e baixos a descoberto), temas que não se restringem à "interpretação ou aplicação" da CNUDM e foram expressamente excluídos pela China dos procedimentos compulsórios de solução de disputas pela Declaração de 2006. A corte arbitral também avaliou de forma incorreta que não existia um acordo entre as Filipinas e a China para resolver as disputas através de negociações e, novamente, equivocou-se ao entender que as Filipinas tinham preenchido a obrigação de trocar opiniões, prevista no artigo 283 da CNUDM.

\section{AS QUESTÕES AMBIENTAIS NO LAUDO ARBITRAL (MÉRITO): AS ALEGAÇÕES DAS FILIPINAS E A “DEFESA” DA CHINA}

Os aspectos ambientais presentes no LAM estão concentrados entre os parágrafos 815 e 993, em que a corte arbitral analisou os pleitos n. 11 e 12(b) das Filipinas, inseridos no subtítulo

\footnotetext{
36 Traduções do original: "The Tribunal considers that the better view is that Article 281 requires some clear statement of exclusion of further procedures"; "[...] even if the Tribunal were to accept that recourse to Part XV dispute settlement procedures may be implicitly excluded, the Tribunal finds that no such exclusion can be implied from the DOC".
} 
“Alegado incumprimento de proteger e preservar o meio ambiente marinho", divididos em duas questões. A primeira afirma que ao tolerar e dar suporte para práticas pesqueiras predatórias por navios de sua bandeira, a China violou suas obrigações de proteger e preservar o meio marinho, nos termos da CNUDM, em Scarborough Shoal, Second Thomas Shoal, Cuarteron Reef, Fiery Cross Reef, Johnson Reef, Hughes Reef, Gaven Reef e Subi Reef. ${ }^{37} 0$ segundo alega que a ocupação da China e as atividades de construção em Cuarteron Reef, Fiery Cross Reef, Johnson Reef, Hughes Reef, Gaven Reef (norte), Subi Reef e Mischief Reef violam os deveres que a China tem de proteger e preservar o meio ambiente marinho, conforme o estipulado na CNUDM.

Como mencionado anteriormente, o LAJA entendeu que no que se refere ao pleito $\mathrm{n}$. 11, a corte arbitral tinha jurisdição porque a disputa envolvia a interpretação e a aplicação dos artigos 192 e 194 da CNUDM, que impõem aos Estados obrigações para proteger e preservar o meio ambiente marinho. No tocante à totalidade do pleito $n$. 12, a corte postergou a análise para realizá-la conjuntamente com a decisão de mérito.

\subsection{As alegações das Filipinas}

As alegações da Filipinas no que dizem respeito aos aspectos ambientais podem ser resumidas em duas questões: práticas pesqueiras predatórias e atividades construtivas danosas, ambas prejudiciais ao frágil e diversificado ecossistema do Mar da China Meridional.

\subsubsection{Práticas pesqueiras predatórias e exploração de espécies ameaçadas ou em perigo de extinção}

As Filipinas juntaram diversos documentos que comprovariam o envolvimento, desde o final dos anos 1990, de navios de bandeira chinesa em práticas pesqueiras predatórias ao meio ambiente marinho e na exploração de espécies ameaçadas ou em perigo de extinção, em diversos pontos do Mar da China Meridional. Ainda de acordo com as alegações das Filipinas, em navios chineses apreendidos foram encontrados cianeto, dinamite, detonantes e explosivos utilizados nesse tipo de atividade pesqueira. Autoridades das Filipinas também disseram ter

\footnotetext{
37 Inicialmente, o pleito n. 11 requeria o exame somente sobre as práticas pesqueiras em Scaraborough Shoal e Second Thomas Shoal. Contudo, durante a audiência de mérito em 30 de novembro de 2015, as Filipinas solicitaram que o pleito n. 11 fosse emendado para abranger também os ambientes marinhos em Cuarteron Reef, Fiery Cross Reef, Johnson Reef, Hughes Reef, Gaven Reef e Subi Reef. A corte arbitral entendeu que as emendas eram relacionadas ou incidentais ao pleito original e não envolvia a introdução de novas disputas entre as Partes.
} 
apreendido em navios chineses diversas espécies ameaçadas de tubarões, enguias, tartarugas marinhas e corais. Há ainda relatos de que pescadores também estariam cortando recifes com hélices de maneira generalizada e apreendendo amêijoas gigantes (para. 829-830 LAM).

As Filipinas alegaram que a China tolerava, quando não mesmo incentivava, essas práticas ambientalmente destrutivas por seus nacionais e falhava no seu dever de proteger e preservar o meio ambiente marinho, conforme o disposto nos artigos 192 e 194 da CNUDM (para. 894 LAM).

\subsubsection{Atividades chinesas de construção em sete formações insulares nas ilhas Spratly}

A segunda questão ambiental trazida pelas Filipinas referia-se as atividades de construção realizadas pela China em sete características geológicas nas ilhas Spratly: Cuarteron Reef, Fiery Cross Reef, Gaven Reef (norte), Johnson Reef, Hughes Reef, Subi Reef e Mischief Reef. Segundo os documentos juntados pelas Filipinas, a China entre o início dos anos 1990 e 2013 conduziu atividades de construção e recuperação de terras (land reclamation) nessas áreas, utilizando-se desde madeira e fibra de vidro até a instalação de barras de ferro e concretagem (para. 853 LAM). Constam do LAM diversas fotos anteriores e posteriores a essas construções.

Em relação as atividades construtivas prejudiciais ao ambiente marinho, as Filipinas afirmaram que o processo de recuperação de terras em Mischief Reef e outros pontos do Mar da China Meridional exerce um profundo impacto ambiental e constitui a perda mais rápida e durável de recifes de corais provocada por atividades humanas jamais registradas (para. 904 LAM).

\subsection{A "defesa" da China}

Apesar da negativa em participar de qualquer ato relacionado com a arbitragem no Mar da China Meridional, a corte arbitral entendeu que a posição da China no que se referia as submissões n. 11 e 12(b) das Filipinas poderia ser discernida a partir de declarações oficiais contemporâneas (para. 912 LAM).

\subsubsection{Práticas pesqueiras predatórias e exploração de espécies ameaçadas ou em perigo de extinção}


Em relação aos incidentes relatados pelas Filipinas ocorridos entre 1998 e 2006, em que barcos de bandeira chinesa foram apreendidos e depois liberados sem a carga pela Marinha das Filipinas na área de Scarborough Shoal, o laudo arbitral registrou que a China sempre afirmou sua soberania na região e rejeitou a interferência das autoridades das Filipinas na área (para. 913 LAM).

No que se referia aos aspectos ambientais propriamente ditos, a corte arbitral citou três manifestações de autoridades chinesas entre 2000 e 2001, que, entre outros aspectos, manifestavam preocupação com a utilização de dinamite em atividades pesqueiras e que era contrária à prática de pesca ilegal; no tocante à apreensão de tartarugas marinhas e corais, a China afirmava que tinha suas próprias leis sobre o tema e que os violadores seriam devidamente punidos (para. 913 LAM).

A corte arbitral também registrou uma manifestação de maio de 2015, em que a China como parte da Convenção sobre Diversidade Biológica (CDB) e da Convenção sobre o Comércio Internacional das Espécies da Flora e Fauna Selvagens em Perigo de Extinção (CITES) -, afirmou que "iria cumprir rigorosamente as previsões da Convenção e honrar suas obrigações de boa fé" (para. 915 LAM). ${ }^{38}$

\subsubsection{Atividades chinesas de construção em sete formações insulares nas ilhas Spratly}

Examinando declarações e outras manifestações de autoridades chinesas, a corte arbitral citou trecho da exposição do porta-voz do Ministério dos Negócios Estrangeiros da China de abril de 2015 que comenta as atividades de construção em Mischief Reef:

Os projetos de construção da China em ilhas e recifes passaram por avaliações científicas e testes rigorosos. Colocamos igual ênfase na construção e na proteção seguindo altos padrões de proteção ambiental e levando em consideração a proteção do ambiente ecológico e dos recursos pesqueiros. 0 ambiente ecológico do Mar da China Meridional não será degradado. No futuro tomaremos medidas adicionais para monitorar e proteger o ambiente ecológico das águas, ilhas e recifes (para. 917 LAM). ${ }^{39}$

\footnotetext{
38 Tradução do original: "[China] will strictly observe provisions of the conventions and honour her obligations in good faith."

39 Tradução do original: "China's construction projects on the islands and reefs have gone through scientific assessments and rigorous tests. We put equal emphasis on construction and protection by following a high standard of environmental protection and taking into full consideration the protection
} 
A corte arbitral também citou trechos de um relatório elaborado pelo State Oceanic Administration (SOA) da China, de junho de 2015 sobre atividades de construção em recifes nas ilhas Nansha (ou Spratly), em que se registra que "diversas medidas protetivas foram adotadas nos estágios de planejamento, desenho e construção. Bons resultados foram obtidos, e os impactos ecológicos nos corais de recifes é parcial, temporário, controlável e recuperável" (para. 922 LAM). ${ }^{40}$

\section{AS CONSIDERAÇÕES DA CORTE ARBITRAL SOBRE OS ASPECTOS AMBIENTAIS}

Antes de enfrentar as questões ambientais referidas nos pleitos n. 11 e 12(b) das Filipinas, a corte arbitral considerou dois aspectos preliminares: primeiro o tema da sua jurisdição, em especial sobre o pleito n. 12(b) que ficara pendente no LAJA, seguido de uma análise das disposições da CNUDM relevantes ao exame dos temas ambientais.

\subsection{Jurisdição}

À título inicial a corte arbitral ratificou o entendimento de que tinha jurisdição no tocante às questões sobre a proteção e a preservação do meio ambiente marinho em diversas formações insulares no Mar da China Meridional (pleito n. 11), já que se tratava de interpretação e aplicação dos artigos 192 e 194 da CNUDM e não sobre à soberania dessas características ou delimitação marítima entre os dois países (para. 926 LAM). A corte arbitral tampouco considerou que o artigo 298 da CNUDM colocasse qualquer tipo de obstáculo jurisdicional para a análise do pleito n. 11 (para. 928 LAM).

Em relação ao pleito n. 12(b), cujo aspecto jurisdicional ficara pendente no LAJA, visto que a demanda poderia recair na exceção prevista no artigo 298.1(b) da CNUDM (controvérsias relativas a atividades militares), a corte arbitral ressaltou que diversos pronunciamentos de

of ecological environment and fishing resources. The ecological environment of the South China Sea will not be damaged. We will take further steps in the future to monitor and protect the ecological environment of relevant waters, islands and reefs".

40 Tradução do original: "many protection measures were adopted in the stages of planning, design, and construction. Good results have been obtained, and the ecological impact on the coral reefs is partial, temporary, controllable, and recoverable". 
autoridades chinesas afirmavam que as instalações e a construção de ilhas tinham como objetivo atividades civis. Citando, por exemplo, uma declaração do porta-voz do Ministério dos Negócios Estrangeiros de abril de 2015 em que este afirmava que as construções nas ilhas Spratly buscavam:

[...] otimizar suas funções, melhorando as condições de vida e trabalho do pessoal lá posicionado, aperfeiçoando a segurança da soberania territorial e os interesses e direitos marítimos, bem como aprimorando a responsabilidade internacional e as obrigações de busca e resgate da China, prevenção e mitigação de desastres, pesquisa marinha, observação meteorológica, proteção ambiental, segurança na navegação, serviços de produção de pesca e outras áreas (para. 936). ${ }^{41}$

Outra menção importante nesse sentido foi uma do próprio Presidente Xi Jinping que em setembro de 2015 declarou que as "importantes atividades de construção que a China vem conduzindo nas ilhas do sul - ilhas Nansha não objetivam ou impactam nenhum país, e a China não tem intenção de buscar a militarização" (para. 937 LAM). ${ }^{42}$

Com base nessas declarações de autoridades chinesas, a corte arbitral entendeu que "não considerará atividades de natureza militar quando a própria China de maneira consistente e oficial refuta tais classificações e afirmou o oposto por sua mais alta hierarquia" (para. 938 LAM). ${ }^{43}$ Dessa maneira, considerando as atividades de construção empreendidas pela China como de natureza civil e por isso excluída do escopo da exceção prevista no artigo 298.1(b), a corte arbitral concluiu que tinha jurisdição para examinar o pleito n. 12(b) das Filipinas.

\subsection{Disposições relevantes da CNUDM}

Examinando o artigo 192 da CNUDM que dispõe que "os Estados têm a obrigação de proteger e preservar o meio marinho", a corte arbitral mesmo reconhecendo os termos genéricos do artigo, considerou que o artigo 192 impõe um dever aos Estados-partes, cujo conteúdo é preenchido por outros dispositivos da Parte XII e outras regras aplicáveis de direito

\footnotetext{
${ }^{41}$ Tradução do original: "[...] optimizing their functions, improving the living and working conditions of personnel stationed there, better safeguarding territorial sovereignty and maritime rights and interests, as well as better performing China's international responsibility and obligation in maritime search and rescue, disaster prevention and mitigation, marine science and research, meteorological observation, environmental protection, navigation safety, fishery production service and other areas".

42 Tradução do original: "relevant construction activities that China [is] undertaking in the island of South - Nansha Island do not target or impact any country, and China does not intend to pursue militarization".

43 Tradução do original: "will not deem activities to be military in nature when China itself has consistently and officially resisted such classifications and affirmed the opposite at the highest levels".
} 
internacional, tais como a CDB e a CITES. A corte arbitral ainda acrescentou que as regras de direito internacional referentes ao meio ambiente requerem que o Estado assegure que as atividades sob sua jurisdição e controle respeitem o meio ambiente dos demais Estados e também em áreas além das jurisdições nacionais. Assim, os Estados têm o dever de prevenir, ou pelo menos, mitigar sérios danos ao meio ambiente quando das atividades de construção em larga escala (para. 941 LAM).

Um dos aspectos inovadores do LAM foi a abordagem expansiva que a corte arbitral fez da obrigação de "devida diligência" no contexto do direito do mar. A corte insistiu que a Parte XII da Convenção impõe um pesado "nível de vigilância” e, consequentemente, a corte impôs um padrão muito alto de "devida diligência”. Uma abordagem radicalmente distinta da adotada, por exemplo, pela Câmara dos Fundos Marinhos do Tribunal Internacional do Direito do Mar.44

A corte arbitral se referiu a duas decisões de tribunais internacionais para reforçar seu entendimento sobre a obrigação de proteger e preservar o meio marinho, em especial no tocante à poluição do meio marinho (artigo 194 da CNUDM).

Primeiramente, ao parecer consultivo solicitado pela Sub-Regional Fisheries Commission (SRFC) ao Tribunal Internacional do Direito do Mar, em que se esclareceu a obrigação que o Estado da bandeira tem de assegurar que os navios que arvorem sua bandeira não se envolvam em atividades que prejudiquem as responsabilidades por ele assumidas sob a CNUDM no que diz respeito à conservação dos recursos vivos e à obrigação de proteger e preservar o meio marinho. ${ }^{45} \mathrm{E}$, posteriormente, ao caso "Fábricas de Celulose no Rio Uruguai” julgado pela $\mathrm{CIJ}$ que asseverou que a obrigação de "assegurar" é uma obrigação de conduta que requer "devida diligência", em que o Estado da bandeira não deve simplesmente adotar regras e medidas apropriadas, mas também um certo nível de vigilância no seu cumprimento e no exercício do seu controle administrativo. Agregando que quando do recebimento de relatos de não-cumprimento por parte de outro Estado, o Estado da bandeira está obrigado a investigar o assunto e, se apropriado, tomar as medidas necessárias para sanar a situação, bem como informar suas ações ao Estado que relatou o ocorrido (para. 944 LAM). ${ }^{46}$

Por fim, a corte arbitral ainda examinou outros dois dispositivos da CNUDM, os artigos 123 e 206. O primeiro refere-se à cooperação regional em mares semifechados, como é o caso do

\footnotetext{
${ }^{44}$ MBENGUE, Makane Moise. The South China Sea Arbitration: Innovations in Marine Environmental FactFinding and Due Diligence Obligations. AJIL Unbound, vol. 110, 2016, p. 285-286.

45 INTERNATIONAL TRIBUNAL FOR THE LAW OF THE SEA (ITLOS). Request for an Advisory Opinion Submitted by the Sub-Regional Fisheries Commission (SRFC) (Case n. 21), 2 April 2015.

46 INTERNATIONAL COURT OF JUSTICE (ICJ). Pulp Mills on the River Uruguay (Argentina v. Uruguay). Judgment, ICJ Reports 2010. p. 14.
} 
Mar da China Meridional, dispondo que os Estados costeiros "deveriam cooperar entre si no exercício dos seus direitos e no cumprimento dos seus deveres nos termos da presente Convenção" (para. 946 LAM). Enquanto o artigo 206 da CNUDM assegura que as atividades projetadas com possíveis efeitos danosos sejam controladas de maneira eficaz e que os demais Estados sejam informados dos seus riscos potenciais (para. 947-948 LAM).

\subsection{Práticas pesqueiras predatórias e exploração de espécies ameaçadas ou em perigo de extinção}

Baseando-se em relatórios de autoridades navais e da guarda costeira filipina, em notas diplomáticas e em fotografias juntadas aos autos, a corte arbitral deu-se por satisfeita ao constatar o envolvimento de navios de bandeira chinesa na exploração de espécies ameaçadas ou em perigo de extinção na área de Scarborough Shoal, em diversas oportunidades entre 1998 e 2012 (para. 950-951 LAM).

Citando apreensões realizadas em embarcações de bandeira chinesa por navios da Marinha das Filipinas, em que haviam diversas espécies de tartarugas marinhas, amêijoas gigantes e corais, todas protegidas pela Convenção CITES, de que tanto as Filipinas como a China são Partes, a corte arbitral considerou que a não adoção de medidas para impedir tais práticas constituía uma violação aos artigos 192 e 194.5 da CNUDM (para. 960 LAM).47

Apesar de registrar uma nota verbal da China em que esta assegurou às Filipinas que “atribui grande importância à proteção ambiental e que os infratores são tratados de acordo com as leis e regulamentos chineses" (para. 961 LAM) ${ }^{48}$, a corte arbitral afirmou que não encontrou nenhuma comprovação de que pescadores chineses envolvidos em pesca ilegal tenham sido processados sob as leis chinesas (para. 915 LAM).

A corte arbitral foi particularmente dura nesse ponto com a China ao considerar que:

Não há prova nos autos que indicariam que a China tomou qualquer medida para executar tais regras e providências [artigos 192 e 194.5] contra pescadores envolvidos na pesca de espécies ameaçadas. Na verdade, pelo menos com relação aos incidentes de abril de 2012, as evidências indicam diretamente em sentido contrário. A China tinha conhecimento da extração de amêijoas gigantes.

\footnotetext{
${ }^{47}$ Artigo 194.5 da CNUDM: "As medidas tomadas de conformidade com a presente parte devem incluir as necessárias para proteger e preservar os ecossistemas raros ou frágeis, bem como o habitat de espécies e outras formas de vida marinha em vias de extinção, ameaçadas ou em perigo".

48 Tradução do original: "[...] attaches great importance to environmental protection and violators are dealt with in accordance with Chinese laws and regulations".
} 
Não simplesmente fez vista grossa para a prática. Mais do que isso, forneceu embarcações governamentais armadas para proteger os navios de pesca. [...] A corte, portanto, não hesita em encontrar violações da China aos artigos 192 e 194.5 da Convenção [...] (para. 964 LAM). ${ }^{49}$

Entretanto, a corte arbitral desconsiderou a origem do incidente de abril de 2012. Foram embarcações de bandeira das Filipinas que inicialmente de modo ilegal e por meio do uso da força foram a bordo das embarcações pesqueiras chinesas, violando a soberania da China. Em razão desse primeiro incidente e com a finalidade de proteger sua soberania na região, a vida, a segurança e as propriedades dos pescadores chineses é que navios da China foram enviados à região. ${ }^{50}$

Desconhecendo, ou talvez desconsiderando, a origem do incidente de abril de 2012, a corte arbitral mais do que condenar a China no descumprimento do dever de devida diligência, acusou o país, com todas as letras, de "fazer vista grossa" e de proteger "os pescadores envolvidos na pesca de espécies ameaçadas", empregando uma linguagem notadamente virulenta, raramente vista em decisões de tribunais e cortes internacionais.

Baseando-se em diversas informações fornecidas pelas Filipinas que comprovariam que navios de pesca de bandeira chinesa utilizavam-se de cianeto e dinamite em práticas pesqueiras, a corte arbitral também considerou que tais atos violavam os artigos 192, 194.2 e 194.5 da CNUDM. No entanto, nesse aspecto, a corte citando o artigo 30 da lei chinesa sobre pesca - que proíbe o uso de explosivos, venenos, eletricidade e outros métodos semelhantes - reconheceu que adoção de leis e regulamentos é um componente importante na devida diligência exigida pela CNUDM aos Estados, mas agregou que aos "Estados também é exigido que adotem certos níveis de vigilância no cumprimento e no controle de certas regras, mas há pouco nos autos sugerindo que a China deixou de fazer isso com respeito a pesca com dinamite e cianeto" (para. 974 LAM). ${ }^{51}$

\footnotetext{
${ }^{49}$ Tradução do original: "There is no evidence in the record that would indicate that China has taken any steps to enforce those rules and measures against fishermen engaged in poaching of endangered species. Indeed, at least with respect to the April 2012 incidents, the evidence points directly to the contrary. China was aware of the harvesting of giant clams. It did not merely turn a blind eye to this practice. Rather, it provided armed government vessels to protect the fishing boats. [...] The Tribunal therefore has not hesitation in finding that China breached its obligation under Article 192 and 194(5) of the Convention [....".

${ }^{50}$ CHINESE SOCIETY OF INTERNATIONAL LAW (CSIL). The South China Sea Arbitration Awards: A Critical Study. Chinese Journal of International Law, vol. 17, 2018. p. 578.

51 Tradução do original: "States are also required to adopt a certain level of vigilance in the enforcement and control of the rules, but there is little in the record to suggest that China has failed to do so with respect to dynamite and cyanide fishing".
} 
Nesse ponto, a corte arbitral adotou uma interpretação peculiar e consideravelmente rigorosa do dever de devida diligência, ou seja, ao invés de considerar uma obrigação de conduta, a corte arbitral aplicou o dever como uma obrigação de resultado. A corte arbitral de modo deliberado desconsiderou o elemento "de acordo com suas capacidades" no dever de devida diligência, isto é, não é exigível aos Estados que tomem medidas além das suas capacidades.

Além disso, uma vez mais a corte arbitral excedeu-se ao afirmar que "não há prova nos autos que indicariam que a China tomou qualquer medida para executar tais regras e providências contra pescadores envolvidos na pesca de espécies ameaçadas". Segundo um estudo da Sociedade Chinesa de Direito Internacional (SCDI) a China além de adotar legislação específica sobre questões ambientais - a lei sobre proteção da vida selvagem (adotada em 1989, emendada em 2004 e 2009 e revista em 2016), a lei sobre pescas (adotada em 1989, emendada em 2000, 2004, 2009 e 2013) e os regulamentos sobre a proteção dos animais aquáticos selvagens (adotada em 1993 e emendada em 2011) que preveem sanções em casos de violações também impôs penas aos pescadores envolvidos em tais práticas, citando diversas condenações entre 2007 e 2014 ocorridas em diferentes províncias do sul da China, o que corroboraria os esforços do país em proteger as espécies ameaçadas.52

\subsection{Atividades chinesas de construção em sete formações insulares nas ilhas Spratly}

Citando o descrito entre os parágrafos 852 e 890 sobre as atividades de construção conduzidas pela China, que demonstrariam que até o final de 2013, teriam sido acrescentados em cima dos recifes de corais 12,8 milhões de metros quadrados de terra - à partir de milhões de toneladas de areias, rochas e corais dragadas do leito do mar -, a corte arbitral considerou que "não há dúvida que o programa de construção de ilhas artificiais é parte de uma política oficial da China e um programa implementado por órgãos do Estado chinês" (para. 976 LAM).53

Antes de analisar o impacto das construções de ilhas que vem sendo empreendido pela China, a corte arbitral recordou que não se trata propriamente de um processo novo. Ao contrário, vem sendo conduzido nos últimos vinte anos não só pela China, mas também pelas

\footnotetext{
${ }^{52}$ CHINESE SOCIETY OF INTERNATIONAL LAW (CSIL). The South China Sea Arbitration Awards: A Critical Study. Chinese Journal of International Law, vol. 17, 2018, p. 575-582.

53 Tradução do original: "[...] there is no question that the artificial island-building program is part of an official Chinese policy and program implemented by organs of the Chinese State".
} 
Filipinas e Vietnã. Por outro lado, a corte arbitral salientou que o atual processo desenvolvido pela China excede em muito os projetos de construção anteriores (para. 854 LAM).

Reconhecendo o impacto daquelas construções sobre os recifes, a corte arbitral - com base em relatório de especialistas independentes indicados pela própria corte - concluiu que as atividades de construção recentes impactam os recifes de maneira sem precedentes. Um estudo de 2016 que se utiliza de imagens de satélites - citado no relatório dos especialistas independentes - mostraria que $60 \%$ dos recifes submersos das sete formações insulares referidas teriam sido destruídos (para. 978 LAM).54 De acordo com os pareceres técnicos solicitados pela corte arbitral esse processo de construção e depósito de material poderia afetar os recifes de três maneiras distintas: i) destruição direta dos habitas dos recifes; ii) impactos indiretos sobre organismos bentônicos, tais como corais e algas marinhas; e, iii) impactos indiretos sobre organismos na coluna de água, como peixes e larvas (para. 857 LAM).

Também nesse ponto, a corte arbitral foi bastante rigorosa com a China, ao considerar que:

Com base em provas convincentes, relatórios de especialistas e análise crítica das reivindicações chinesas descritas acima, a corte não tem dúvidas de que as atividades chinesas de construção de ilhas nos sete recifes nas ilhas Spratly causaram danos devastadores e duradouros ao ambiente marinho. A corte da mesma forma identifica que por meio dessas atividades de construção, a China violou a obrigação prevista no artigo 192 de proteger e preservar o meio marinho, conduziu dragagens de tal maneira que poluiu o ambiente marinho com sedimentos em violação ao artigo 194.1 e infringiu seu dever sob o artigo 194.5 de tomar medidas necessárias para proteger e preservar o frágil e raro ecossistema bem como as espécies exauridas, ameaçadas ou em perigo de extinção e outras formas de vida marinha (para. 983 LAM). ${ }^{55}$

Contudo, o estudo preparado pela SCDI destaca alguns pontos importantes. Primeiro, entre a indicação pela corte dos três especialistas encarregados de preparar um relatório sobre

\footnotetext{
${ }^{54}$ Como apontado por Tanaka, indicação de especialistas pela própria corte arbitral e o peso considerável que deu ao seu relatório sobre as atividades de construção em formações insulares contrasta com a prática da Corte Internacional de Justiça. TANAKA, Yoshifumi. The South China Sea arbitration: Environmental obligations under the Law of the Sea Convention. RECIEL, vol. 27, 2018. p. 95.

55 Tradução do original: "Based on the compelling evidence, expert reports, and critical assessment of Chinese claims described above, the Tribunal has no doubt that China's artificial island-building activities on the seven reefs in the Spratly Islands have caused devastating and long-lasting damage to the marine environment. The Tribunal accordingly finds that through its construction activities, China has breached its obligation under Article 192 to protect and preserve the marine environment, has conducted dredging in such a way as to pollute the marine environment with sediment in breach of Article 194(1), and has violated its duty under Article 194(5) to take measures necessary to protect and preserve rare or fragile ecosystems as well as the habitat of depleted, threatened or endangered species and other forms of marine life".
} 
os impactos ambientais da construção e reclamação de terras e a divulgação desse relatório passaram-se apenas 17 dias, concluindo-se que “um período tão curto de tempo está longe de ser suficiente para lidar com uma avaliação científica tão complicada do meio ambiente marinho do Mar da China Meridional". ${ }^{56}$ Segundo, foi um relatório preparado sem a coleta de dados em primeira mão e sem citar qualquer pesquisa específica na área, limitando-se a apresentar impactos semelhantes em outras regiões do mundo. Terceiro, as imagens aéreas que constam do relatório também são fontes discutíveis, já que muitas foram obtidas no website do Center for Strategic \& International Studies, um instituto de posicionamento tendencioso, e em "várias fontes", sem indicação específica da origem onde as imagens foram adquiridas. ${ }^{57}$

À luz do prescrito no artigo 206 da CNUDM que requer que quando "os Estados que tenham motivos razoáveis para acreditar que as atividades projetadas sob sua jurisdição ou controle podem causar uma poluição considerável do meio marinho ou nele provocar modificações significativas e prejudiciais devem avaliar, na medida do possível, os efeitos potenciais dessas atividades para o meio marinho e publicar relatórios sobre os resultados dessas avaliações", a corte arbitral considerou que a China deveria "na medida do possível" ter preparado um estudo de impacto ambiental (EIA) e também ter divulgado os seus resultados (para. 988 LAM).

A corte indicou que a despeito das repetidas afirmativas chinesas de que conduzira tais atividades por meio estudos ambientais, nem a corte, nem os especialistas indicados pela corte e tampouco as autoridades e especialistas indicados pelas Filipinas conseguiram identificar qualquer relatório que se assemelharia a um EIA nos termos do artigo 206 da CNUDM ou mesmo da lei chinesa de 2002 sobre estudos de impacto ambiental (para. 989 LAM).

No entanto, é importante lembrar que o artigo 206 dispõe que “os Estados que tenham motivos razoáveis para acreditar" nos efeitos potenciais dessas atividades para o meio marinho devem avaliar e publicar relatórios de impacto ambiental, ou seja, se o Estado, depois de uma avalição, entender que não existem fundamentos razoáveis para acreditar que as atividades planejadas sob sua jurisdição e controle têm o potencial de causar poluição considerável ou provocar modificações significativas no meio marinho, pode decidir que não há necessidade de preparar um EIA e, portanto, não existem resultados a serem comunicados de acordo com os

\footnotetext{
56 Tradução do original: "Such a short period of time is far from enough for dealing with such a complicated scientific assessment of the South China Sea marine environment".

57 CHINESE SOCIETY OF INTERNATIONAL LAW (CSIL). The South China Sea Arbitration Awards: A Critical Study. Chinese Journal of International Law, vol. 17, 2018, p. 585-586.
} 
artigos 205 e 206 da CNUDM..$^{58}$

A China, entretanto, sempre garantiu que as atividades estavam baseadas em sólidas evidências e minuciosos estudos, e que foram empregadas medidas protetivas em todo o processo de forma a conciliar a construção com a proteção ambiental e o desenvolvimento sustentável das ilhas e recifes. Em meados de junho de 2015, o SOA da China publicou dois documentos em seu website ratificando o entendimento que a construção obedecia aos rigorosos parâmetros do conceito Green Construction, Eco-Friendly Reefs e que inúmeras medidas protetivas tinham sido adotadas durante o planejamento, concepção e a execução da reclamação de terras. Essas medidas tomadas pelas autoridades chinesas comprovariam o dever de devida diligência nos trabalhos de construção. A corte arbitral desprezou essas informações, baseando-se exclusivamente no relatório dos especialistas por ela indicados. ${ }^{59}$

Se por um lado, a corte reconheceu que não podia fazer nenhuma afirmativa definitiva de que a China tivesse elaborado um EIA, tampouco podia afirmar que a China tivesse deixado de fazê-lo à luz das repetidas assertivas de autoridades e cientistas chineses de que tais atividades foram conduzidas por meio de estudos. Por outro lado, a corte entendeu que tais conclusões não seriam necessárias para encontrar uma violação ao artigo 206, já que para cumprir tal obrigação o Estado não deve simplesmente preparar um EIA, mas também deve divulgá-lo (para. 991 LAM). Agindo dessa maneira a corte arbitral inverteu o ônus da prova como indicado acima.

A corte concluiu, por fim, que no tocante as atividades de construção nas mencionadas sete formações insulares, a China violou as obrigações assumidas nos artigos 192, 194.1, 194.5, 123 e 206 da CNUDM (para. 993 LAM). Uma prática - conforme reconhecido pelo próprio LAM também realizada pelas Filipinas e Vietnã, mas nesse caso, seu eventual impacto ambiental foi minimizado.

\section{CONCLUSÃO}

O Mar da China Meridional está no centro de um conjunto de interesses de naturezas diversas, envolvendo Estados regionais e não-regionais. As controvérsias analisadas na “Arbitragem do Mar da China Meridional” são apenas parte de um cenário político e jurídico mais

${ }^{58}$ CHINESE SOCIETY OF INTERNATIONAL LAW (CSIL). The South China Sea Arbitration Awards: A Critical Study. Chinese Journal of International Law, vol. 17, 2018. p. 591.

59 CHINESE SOCIETY OF INTERNATIONAL LAW (CSIL). The South China Sea Arbitration Awards: A Critical Study. Chinese Journal of International Law, vol. 17, 2018, p. 586-587. 
intrincado e de solução definitiva muito mais desafiante.

Para prosseguir com o julgamento - apesar da oposição chinesa em participar de qualquer ato da arbitragem - a corte arbitral teve que desconsiderar um fator inerente nas disputas da região, ou seja, a questão da soberania territorial sobre diversas formações insulares, além de desprezar possíveis questões sobre delimitação marítima, controvérsias essas que afastariam sua jurisdição para julgar os pleitos filipinos.

A alegada pretensão das Filipinas de que o que estava em disputa era somente sobre "a interpretação e aplicação da CNUDM" acabou encontrando eco entre os membros da corte arbitral, que tornaram a questão subsidiária em principal. No entanto, as recorrentes menções tanto no LAJA como no LAM de que os pleitos filipinos não versavam sobre a soberania territorial, evidencia o posicionamento frágil adotado pela corte e que foi criticado por parte de inúmeros internacionalistas.

O desconforto da corte arbitral com a não presença chinesa em todas as etapas da arbitragem parece particularmente evidente quando do exame das questões ambientais trazidas pelas Filipinas. Em raras oportunidades, um tribunal ou uma corte internacional foi tão severo com um Estado. Na análise dos pleitos filipinos n. 11 e 12(b) a corte arbitral desconsiderou e/ou desqualificou todas as ações empreendidas pela China na região, apesar das declarações oficiais do cumprimento da lei chinesa aplicável a práticas pesqueiras ilegais e da existência de estudos que comprovariam que os eventuais danos decorrentes da construção de ilhas podem ser revertidos.

\section{REFERÊNCIAS}

ASSOCIATION OF SOUTHEAST ASIAN NATIONS (ASEAN). Declaration on the Conduct of Parties in the South China Sea (DOC), assinada em 4 de novembro de 2002. Disponível em:

http: //asean.org/?static_post=declaration-on-the-conduct-of-parties-in-the-south-china-sea-2. Acesso em: 20 dez. 2019.

BECKMAN, Robert. The UN Convention on the Law of the Sea and the Maritime Disputes in the South China Sea. American Journal of International Law, vol. 107, n. 1, p. 142-163, 2013.

CHINA. Position Paper of the Government of the People's Republic of China on the Matter of Jurisdiction in the South China Sea Arbitration Initiated by the Republic of the Philippines. Disponível em: https://www.fmprc.gov.cn/nanhai/eng/snhwtlcwi_1/t1368895.htm. Acesso em: 20 dez. 2019.

CHINESE SOCIETY OF INTERNATIONAL LAW (CSIL). The South China Sea Arbitration Awards: A Critical Study. Chinese Journal of International Law, vol. 17, 2018, p. 207-748. 
INTERNATIONAL COURT OF JUSTICE (ICJ). Maritime Delimitation and Territorial Questions between Qatar and Bahrain. Merits, Judgment. ICJ Reports 2001. p. 40.

INTERNATIONAL COURT OF JUSTICE (ICJ). Pulp Mills on the River Uruguay (Argentina $v$. Uruguay). Judgment, ICJ Reports 2010. p. 14.

INTERNATIONAL TRIBUNAL FOR THE LAW OF THE SEA (ITLOS). Request for an Advisory Opinion Submitted by the Sub-Regional Fisheries Commission (SRFC) (Case n. 21). 2 April 2015.

LIN, Kun-Chin; GERTNER, Andrés Villar. Maritime Security in the Asia Pacifc: China and the Emerging Order in the East and South China Seas. London: The Royal Institute of International Affairs/Chatham House, 2015.

MBENGUE, Makane Moise. The South China Sea Arbitration: Innovations in Marine Environmental Fact-Finding and Due Diligence Obligations. AJIL Unbound, vol. 110, 2016, p. 285-289.

NORDQUIST, Myron H. PHALEN, William G. Interpretation of UNCLOS Article 121 and Itu Aba (Taiping) in the South China Sea Arbitration. In: NORDQUIST, Myron H.; MOORE, John Norton; LONG, Ronán (eds.). International Marine Economy: Law and Policy. Leiden: Brill, 2017, p. 378.

PERMANENT COURT OF ARBITRATION (PCA). PCA Case no. 2013-19, In the matter of an arbitration before an arbitral tribunal constituted under Annex VII to the 1982 United Nations Convention on the Law of the Sea between the Republic of the Philippines and the People's Republic of China, Award on Jurisdiction and Admissibility, 29 October 2015. Disponível em: https://pcacases.com/web/sendAttach/2579. Acesso em: 20 dez. 2019.

PERMANENT COURT OF ARBITRATION (PCA). PCA Case no. 2013-19, In the matter of the South China Sea arbitration before an arbitral tribunal constituted under Annex VII to the 1982 United Nations Convention on the Law of the Sea between the Republic of the Philippines and the People's Republic of China, Award, 12 July 2016. Disponível em:

https://pcacases.com/web/sendAttach/2086. Acesso em: 20 dez. 2019.

PHILIPPINES. Arbitration under Annex VII of the United Nations Convention on the Law of the Sea. Republic of the Philippines v. People's Republic of China. Memorial of the Philippines, vol. I, 30 March 2014. Disponível em: https: //files.pca-

cpa.org/pcadocs/Memorial\%20of\%20the\%20Philippines\%20Volume\%20I.pdf. Acesso: 20 dez. 2019.

PHILIPPINES. Republic of Philippines' Notification of Statement and Claim, de 22 de janeiro de 2013, para. 7. Disponível em: https://www.gov.ph/documents/20147/151042/20130122Notification-and-Statement-of-Claim-on-West-Philippine-Sea.pd. Acesso: 20 dez. 2019.

SILVA, Alexandre Pereira da. Aspectos jurídicos e políticos das disputas no Mar da China Meridional. In: COSTA LIMA, Marcos (org.). Perspectivas asiáticas. Rio de Janeiro: Centro Internacional Celso Furtado de Políticas para o Desenvolvimento, 2016. p. 271-299.

SONG, Yann-Huei; ZOU, Keyuan. Maritime Legislation on Mainland China and Taiwan: Developments, Comparison, Implications, and Potential Challenges for the United States. Ocean Development \& International Law, vol. 31, 2000, p. 303-345. 
SOONS, Alfred H. A.; KWIATKOWSKA, Barbara. Entitlement to Maritime Areas of Rocks Which Cannot Sustain Human Habitation or Economic Life their Own. Netherlands Yearbook of International Law, vol. 21, 1990, p. 139-181.

TANAKA, Yoshifumi. The South China Sea arbitration: Environmental obligations under the Law of the Sea Convention. RECIEL, vol. 27, 2018, p. 90-96

TZENG, Peter. Ukraine v. Russia and Philippines v. China: Jurisdiction and Legitimacy. Denver Journal of International Law and Policy, v. 46, n. 1, 2017, p. 1-19.

UNITED NATIONS. Status of Treaties. United Nations Convention on the Law of the Sea. Disponível: https://treaties.un.org/pages/ViewDetailsIII.aspx?src=TREATY\&mtdsg_no=XXI6\&chapter=21\&Temp=mtdsg3\&clang=_en. Acesso em: 20 dez. 2019.

WHOMERSLEY, Chris. The South China Sea: The Award of the Tribunal in the Case Brought by Philippines against China - A Critique. Chinese Journal of International Law, n. 15, 2016, p. 239-264.

YEE, Sienho. The South China Sea Arbitration: The Clinical Isolation and/or One-sided Tendencies in the Philippines' Oral Arguments. Chinese Journal of International Law, vol. 14, 2015, p. 423-435.

ZOU, Keyuan. The South China Sea. In: ROTHWELL, Donald; OUDE ELFERINK, Alex; SCOTT, Karen; STEPHENS, Tim (eds.). The Oxford Handbook of the Law of the Sea. Oxford: Oxford University Press, 2015, p. 626-646.

Recebido em: 23.12.2019 / Aprovado em: 22.04.2021 / Publicado em: 29.09.2021

\section{COMO FAZER REFERÊNCIA AO ARTIGO (ABNT):}

SILVA, Alexandre Pereira da. Jurisdição e aspectos ambientais na arbitragem do Mar da China Meridional (Filipinas vs. China). Revista Eletrônica do Curso de Direito da UFSM, Santa Maria, RS, v. 15, n. 3, e53336, set./dez. 2020. ISSN 1981-3694. DOI: http://dx.doi.org/10.5902/1981369441691. Disponível em: https://periodicos.ufsm.br/revistadireito/article/view/41691. Acesso em: dia mês. ano.

Direitos autorais 2021 Revista Eletrônica do Curso de Direito da UFSM

Editores responsáveis: Rafael Santos de Oliveira e Angela Araujo da Silveira Espindola

Esta obra está licenciada com uma Licença Creative Commons Atribuição-NãoComercial-SemDerivações 4.0 Internacional.

\section{SOBRE O AUTOR}

AleXANDRe Pereira da Silva

Professor e Pesquisador Associado no China Institute of Boundary and Ocean Studies, Wuhan University, Wuhan, China. PósDoutor em Direito pela Schulich School of Law, Dalhousie University, Halifax, Canadá. 